\title{
LA PARTICIPACIÓN POLÍTICA DE JÓVENES ADOLESCENTES EN EL CONTEXTO URBANO ARGENTINO. PUNTOS PARA EL DEBATE
}

\author{
GRACIELA BATALLÁN, ${ }^{*}$ SILVANA CAMPANINI,** \\ ELÍAS PRUDANT, $* * *$ IARA ENRIQUE**** \\ Y SOLEDAD CASTRO $* * * * *$
}

\begin{abstract}
RESUMEN
Los fundamentos jurídico-institucionales que organizan la política —entendida aquí como prácticas reguladas a través de las cuales los sujetos participan de la dirección y gobierno de la sociedad en la que son miembros- excluyen a niños y jóvenes en función de su minoridad. A partir de la reconstrucción del trabajo de campo en dos contextos diferenciados —el Programa La legislatura y la escuela del Poder Legislativo de la Ciudad Autónoma de Buenos Aires y centros de estudiantes de colegios de nivel medio- se analizan aspectos problemáticos relativos a los contenidos y métodos de la participación de los jóvenes en el espacio público.

Las prácticas documentadas por nuestra investigación reactualizan la tensión analizada en la literatura contemporánea respecto al sentido dado a la política y lo que puede entenderse como lo político, a cuya luz se enfocan las preocupaciones y debates que circulan entre los jóvenes. La reflexión profundiza sobre los derroteros de la construcción del bien común que éstos formulan y las formas de la participación política que conciben legítimas, comprometiendo en el análisis los efectos que éstos pudiesen implicar para una eventual democratización de la escuela.
\end{abstract}

\section{PALABRAS CLAVE: INFANCIA, JUVENTUD, CIUDADANÍA, DEMOCRACIA, ESPACIO PÚBLICO}

\footnotetext{
* Profesora Titular Facultad de Filosofía y Letras, Instituto de Ciencias Antropológicas, Universidad de Buenos Aires (UBA), Argentina.

E-Mail: grabat@fibertel.com.ar.

** Docente Facultad de Filosofía y Letras, Instituto de Ciencias Antropológicas, UBA. E-Mail: elentre@gmail.com.

*** Docente Facultad de Filosofía y Letras, Instituto de Ciencias Antropológicas, UBA. E-Mail: eprudant@yahoo.com.

**** Docente Facultad Filosofía y Letras, Instituto de Ciencias Antropológicas, UBA. E-Mail: iaranenrique@hotmail.com.

***** Estudiante avanzada de la carrera de Ciencias Antropológicas, Facultad de Filosofía y Letras, UBA. E-Mail: castro_soledad@hotmail.com.
} 


\title{
A PARTICIPAÇÃO POLÍTICA DE JOVENS ADOLESCENTES NO CONTEXTO URBANO ARGENTINO. APONTAMENTOS PARA DEBATE
}

\begin{abstract}
RESUMO
Os fundamentos jurídico-institucionais que organizam a política —entendida aqui como práticas reguladas através das quais os sujeitos participam da direção e governo de sua sociedade- excluem crianças e jovens por serem menores de idade. A partir da reconstrução do trabalho de campo em dois contextos diferenciados —o Programa A legislatura e a Escola do Poder Legislativo da Cidade Autônoma de Buenos Aires e centros de estudantes de colégios de nível médio- analisam-se aspectos problemáticos relativos aos conteúdos e métodos de participação dos jovens no espaço público.

As práticas documentadas por nossa pesquisa reatualizam a tensão analisada na literatura contemporânea a respeito do sentido dado à política e o que se pode entender como o político, sob cuja luz se enfocam as preocupações e debates que circulam entre os jovens. A reflexão aprofunda os roteiros da construção do bem comum que os jovens elaboram, bem como as formas de participação política que acreditam legítimas, incluindo na análise os impactos que poderiam ter numa eventual democratização da escola.
\end{abstract}

PALAVRAS CHAVE: INFÂNCIA, JUVENTUDE, CIDADANIA, DEMOCRACIA, ESPAÇO PÚBLICO

\section{THE POLITICAL PARTICIPATION OF ADOLESCENTS IN AN ARGENTINIAN URBAN CONTEXT. POINTS FOR DEBATE}

\begin{abstract}
The legal-institutional foundations that organize the policy —acknowledged here as regulated practices through which the subjects participate in the direction and government of the society in which they are members- exclude children and adolescents based on their minority. From the reconstruction of the work in two differentiated contexts - the Program the legislature and the school of the Legislative Power of the Independent City of Buenos Aires and student centers of middle class schoolsproblematic aspects regarding the contents and methods of the participation of the young people in the public space are analyzed.

The practices documented by our investigation make known the tension analyzed in a contemporary literature aspect to the sense given to the policy and what can be understood like as the politician, whose light focuses on the concern and debates that circulate amongst youth. The reflection deepens on the direction of the construction of the communal property which are formulated, and the forms of the participation politics which are conceive as legitimate, jeopardizing in the analysis the effects that these could imply for a possible democratization of the school.
\end{abstract}




\section{EL PROBLEMA TEÓRICO:}

\section{LAS PRÁCTICAS POLÍTICAS DE JÓVENES ADOLESCENTES}

EL NÚCLEO DE ESTA presentación es el análisis de los contenidos y formas de la participación de jóvenes-adolescentes en el campo de las acciones en las cuales se debate el «bien común» o espacio público. Conceptualizar de tal modo las prácticas de estos sujetos implica sumarnos a una vasta discusión dentro de la teoría política contemporánea, para la cual el espacio público sobrepasa los fundamentos jurídico-filosóficos que organizan la política, entendida sólo como prácticas reguladas a través de las cuales los ciudadanos participan del gobierno de la sociedad.

Los ejes del argumento que desarrollaremos se sostienen en la hipótesis de que la invisibilidad de la participación de los jóvenes adolescentes en torno al bien común en general, y dentro de la escuela en particular, se debe a concepciones naturalizadas respecto de la política -en tanto práctica formal y privativa de quienes tienen derecho jurídico por mayoría de edad- y a la vez, a una concepción de infancia y juventud adolescente que los reconoce principalmente en su condición de sujetos dependientes del mundo adulto (Batallán y Campanini, 2005). Dentro de esta concepción, los niños y jóvenes son de hecho excluidos, ya que en tanto menores «no son ciudadanos en pleno derecho» (Adorno, 1973).

Las acciones, demandas y propuestas de los jóvenes adolescentes documentadas por la investigación nos permiten abrir interrogantes sobre cómo conceptualizar su práctica política, a fin de incorporarlas como legítimas en el marco del debate general sobre la profundización de la democracia.

A fin de aclarar el punto de partida de nuestro desarrollo, entendemos conceptualmente a lo político diferenciado de la política, reservando para ésta última el ejercicio de la actividad política o, lo que es lo mismo, las formas institucionalizadas de la democracia representativa (Rosanvallon, 2002; Mouffe, 1999).

A partir de los presupuestos de la teoría liberal angloamericana -que oficia de fundamento jurídico de las instituciones políticas modernas - la conceptualización y construcción del interés general o bien público ha resultado problemática para dar cuenta del proceso creciente de las demandas sociales y de la ampliación democrática. Al concebir a los sujetos como individuos con intereses privados, el interés general sólo puede formularse como resultado del voto (derecho 
privativo de los adultos), o bien como capacidad del Estado, en tanto expresa tal voluntad popular o soberanía. ${ }^{1}$

Los intentos contemporáneos de la filosofía política por resituar el potencial crítico de lo político como proceso que sobrepasa la política se condensan en el concepto de «esfera pública» que elaborara Habermas. En tal formulación, la esfera o espacio público se caracteriza por el conjunto de prácticas deliberativas en la que los individuos, despojados de los intereses del intercambio de los bienes y del trabajo social, «discuten sin restricciones acerca de las cuestiones de interés general» (Habermas, 1986). Este esfuerzo, conjuntamente con el de otros autores, se encuentra interesado por recuperar la concepción republicana de la res pública como resultado de un proceso de amplia participación de sujetos, que no se agota ni se expresa cabalmente en la arquitectura institucional de la política.

La reformulación actual de las teorías clásicas ha considerado, conjuntamente con la crítica anteriormente señalada, el papel de los movimientos sociales en el marco de la globalización y del predominio del capitalismo neoliberal, atendiendo especialmente a aquellos conjuntos sociales con identidad autoasignada (mujeres, minorías étnicas, sexuales, entre otros) que han reclamado nuevas o diferentes formas de inclusión en la ciudadanía. Al analizar el status subordinado de las mujeres, Nancy Frazer ha aportado elementos para profundizar la historicidad de lo que se entiende por público o interés común, sosteniendo que «lo que en el pasado no era público en el sentido de ser un interés común, ha llegado a serlo en el presente» (Frazer,1992). Esto significa que el resultado de la deliberación no puede ser conocido con anterioridad. Junto con el bien común, la idea de contrapúblicos subordinados (que expresan la voz de minorías, agrupamientos y categorías sociales en el espacio público) acuñado por la autora, implica una noción de hegemonía que sobrentiende el dominio de unos intereses por sobre otros ${ }^{2}$ (Frazer, 1992; Laclau y Mouffe, 1985).

1 Para un análisis exhaustivo de los límites y atolladeros de la teoría liberal para comprender el proceso de construcción político cultural de lo que en cada momento histórico se concibe como lo político/la política, véase Somers, 1996/97; y Souza Santos, 1998.

2 De particular importancia para el debate que aquí reproducimos ha sido la confrontación del pensamiento feminista en relación a los principios de la democracia deliberativa, justamente discutiendo una supuesta neutralidad del espacio público, sostenida en la creencia de una eficaz puesta entre paréntesis de las desigualdades sociales, según la cual «éste es 
Si bien la reflexión a la que han dado lugar esta discusión destaca el carácter variable del sujeto político, ampliando la noción de la democracia al entenderla como un proceso de construcción y reconstrucción, tiende a reproducir el sesgo esencialista según el cual los «nuevos» sujetos se reconocen sobre la base de rasgos identitarios comunes (mujeres, minorías lingüísticas, culturales o sexuales), o bien en función de un interés común (a modo de ejemplo, considérese los ecologistas). La noción de sujeto colectivo que resulta así involucrada debe debatirse en el plano epistemológico, dado que la naturaleza del sustrato que permite la identificación mantiene de modo indiscutido un trasfondo culturalista en la constitución de endogrupos, esta vez bajo clasificaciones sociales o de intereses "particulares».

Los aportes a los que nos hemos referido resultan centrales, por tanto, para habilitar la posibilidad de la pregunta acerca de las prácticas políticas de niños y jóvenes, pero contienen los peligro teóricometodológico de circunscribir el campo de análisis a las preocupaciones específicas de esta franja etárea e interpretar sus demandas e intereses solamente bajo el cristal de sus posiciones en la estructura de edades de la sociedad.

El enfoque puesto en juego en nuestra investigación se aparta de la perspectiva culturalista que engloba las manifestaciones simbólicas y contestatarias de los jóvenes según su pertenencia social y ecológica a través de nociones como las de tribu y cultura juvenil, limitando con ello los alcances y preocupaciones que elaboran las nuevas generaciones acerca del espacio público y que trascienden los intereses del endogrupo (Reguillo, 2000; Feixas, 1998; Martín Barbero, 1998; Lesko, 1992; Padawer, 2004).

En términos epistemológicos y en lo que a nuestros sujetos se refiere, se trata de recuperar la perspectiva etnográfica para el conocimiento de la infancia y la juventud adolescente como un sujeto social con potencialidades no conocidas que requieren ser documentadas (Bourdieu, 2000; Batallán y Varas, 2002; Batallán, 2007). En este sentido privilegiamos el registro de numerosas experiencias en las cuales los jóvenes expresan sus intereses y propuestas en torno a los diferentes ámbitos de la vida en común, poniendo en juego explícita o tácitamente las categorías que para ellos hacen manifiesto el estatus de justicia e igualdad. Con esta orientación, la investigación reconstruye tanto los contextos que fundamentan

un lugar vacío culturalmente, desprovisto de un ethos específico y que se acomoda a una neutralidad perfecta» (Frazer, 1992). 
normativamente las prácticas de socialización en la formación ciudadana (la escuela y los programas gubernamentales específicos), como aquellos en los cuales el sentido de las prácticas socializadoras se mantienen en el plano tácito de la interacción (el barrio, la calle, el piquete). ${ }^{3}$ La preocupación recurrente en la tarea de reconstrucción etnográfica ha sido la vinculación que las prácticas y debates llevados a cabo en tales ámbitos establecen con la escuela, puesto que tanto teórica como institucionalmente constituye el único espacio común en cual los jóvenes adolescentes son sujetos constitutivos.

\section{LOS CONTEXTOS EMPÍRICOS DE LA REFLEXIÓN}

Este artículo toma como campo empírico dos contextos institucionales en los que participan jóvenes adolescentes escolarizados. Por una parte, se hace referencia a las acciones que ellos emprenden como parte del Programa La legislatura y la escuela, impulsado por el Poder Legislativo de la Ciudad Autónoma de Buenos Aires desde 1998, y por otro a las actividades y debates político gremiales que desarrollan al interior de los centros de estudiantes de establecimientos secundarios radicados en el área metropolitana de Buenos Aires.

El Programa La legislatura y la escuela fue creado con el objetivo formativo de introducir a niños y jóvenes de escuelas públicas y privadas de la ciudad en las formas del debate democrático. ${ }^{4}$ En su marco, se desarrollan sesiones especiales en las que los alumnos asumen el rol de legisladores por un día y deciden, mediante el debate

3 Proyecto de investigación «Infancia, juventud y política. La participación de un ‘no ciudadano’ en el espacio público». Directora: Graciela Batallán. Además de los autores de este artículo, integran la investigación Ana Padawer, Liliana Dente, Marina Rubinstein, Mónica Córdoba y Gabriela Scarfó. Esta investigación ha recibido financiamiento de la Secretaría de Ciencia y Técnica de la Universidad de Buenos Aires, por el período 2004-2007.

4 La Resolución No151/98 reglamenta el funcionamiento del Programa como actividad bajo la órbita de la Dirección General de Gestión y Participación Ciudadana, dependiente de la Subsecretaría de Labor Parlamentaria, de la legislatura de la Ciudad Autónoma de Buenos Aires. Este Programa se desarrolla ininterrumpidamente desde su creación hasta la fecha, aunque la frecuencia e importancia que le asigna el gobierno de la ciudad depende del cariz político que le imprime el bloque que presida el Programa. 
parlamentario, propuestas que han surgido de sus propias iniciativas. Los proyectos y discusiones a los que dan lugar documentan el amplio espectro en el que niños y jóvenes se construyen como partícipes activos de la sociedad en la que son miembros. ${ }^{5}$

El segundo contexto institucional son los centros de estudiantes secundarios, cuyos objetivos — normativamente previstos - son posibilitar la participación de los alumnos «en cuestiones que sean de su interés» y favorecer el avance de «una cultura política pluralista» en el contexto de los temas que les conciernen y de «aquellos que hacen a la sociedad en su conjunto». ${ }^{6}$

Los ámbitos institucionales referidos heredan las discusiones sociales desplegadas durante las tres décadas de recuperación de la participación ciudadana. Al mismo tiempo, son atravesados por contingencias políticas en las que los jóvenes han sido protagonistas circunstanciales. En el espacio temporal de nuestra investigación tuvo lugar la tragedia de la discoteca «Cro-Magnon», en la que casi dos centenares de personas, mayormente jóvenes, perdieron la vida. Este suceso terminó con la destitución del jefe de gobierno y marcó el inicio de movilizaciones y demandas estudiantiles, en las que predominó una fuerte crítica a los partidos y dirigentes políticos.

El registro etnográfico de las prácticas políticas realizado, da cuenta de la naturaleza y alcances del protagonismo de las nuevas generaciones, y posibilita abrir interrogantes en torno a dos temas teóricamente articulados. Por una parte, las preocupaciones de los niños y jóvenes en relación a la política entendida como la acción mancomunada orientada hacia el bien común y, por otra, aquellas relativas a las formas legitimadas de organización y representación de la acción política en el ámbito de las escuelas.

\section{EL «BIEN COMÚN» COMO CAMPO DE DEBATE}

Los proyectos legislativos elaborados por los niños y jóvenes adolescentes en el marco de la experiencia La legislatura y la escuela, así

5 Para una presentación desarrollada del Programa, véase Batallán et al., 2005.

$6 \quad$ En la ciudad de Buenos Aires los centros de estudiantes se rigen por la ley $\mathrm{N}^{\circ} 137$, sancionada el mismo año que el Programa La legislatura y la escuela, 1998. Ambas normativas han sido fruto de un intenso debate social en torno a los alcances y límites del protagonismo de niños y jóvenes. Para una ampliación de estos temas, véase Batallán et al., 2005. 
como las sesiones parlamentarias en las cuales participan, pueden ser analizados como debates dentro de la esfera pública, tal como ésta fuera conceptualizada por los autores que hemos presentado sintéticamente. Los proyectos que se presentan y la discusión entre los jóvenes de distintas escuelas rebasan ampliamente los objetivos formativos con los cuales se diseñó y difunde la experiencia. ${ }^{7}$ De hecho los proyectos aprobados en estas jornadas educativas, son tomados por algunos parlamentarios, siguen el trámite en las comisiones respectivas, son tratados en las reuniones ordinarias y finalmente se transforman en decisiones estatales. ${ }^{8}$

Invirtiendo el sentido común adultocéntrico que oblitera el protagonismo de las nuevas generaciones, los temas y debates que se despliegan a lo largo del Programa La legislatura y la escuela, se ofrecieron como un documento inesperado en torno a la densidad de las apropiaciones y críticas que los jóvenes realizan sobre la política, mostrando conexiones con el debate general de la sociedad sobre estos temas.

La elaboración de los proyectos que se presentan en la legislatura es precedida por charlas informativas que brindan miembros de ese cuerpo en los establecimientos. ${ }^{9}$ Aunque no constituya una norma formalmente establecida, los alumnos usualmente votan la iniciativa que será objeto de elaboración grupal, dentro un conjunto de propuestas. El proyecto elegido se constituye en un primer producto de decisión y jerarquización colectiva, que incluye asimismo la envergadura de la acción proyectada - esto es, si se plasma en un proyecto de ley, de resolución, o de declaración-y el alcance del proyecto —escolar/institucional, barrial o de alcance

7 Los objetivos perseguidos por el Programa son «el aprendizaje de la práctica democrática a través de la elaboración de propuestas, que tiendan a reflejar las demandas de los diferentes participantes aplicando las reglas del debate legislativo» y «conocer, por intermedio de la vivencia, la experiencia democrática, revalorizando la práctica política» (Resolución $\left.\mathrm{N}^{\circ} 151 / 98\right)$.

8 En diversas ocasiones, las propuestas de niños y jóvenes han alcanzado la aprobación parlamentaria, aunque su autoría queda desdibujada tras la firma del diputado que los «levantó» de estas sesiones especiales e impulsó el trámite parlamentario habitual.

9 Las charlas incluyen los tópicos relativos a la arquitectura constitucional e institucional que organiza el gobierno de la ciudad, las funciones y mecánica de trabajo del poder legislativo, las reglas discursivas que deben respetarse en la redacción del proyecto y en su debate y los objetivos perseguidos con la propuesta. 
social- general. ${ }^{10}$ Un breve paneo por los temas presentados durante el desarrollo de nuestra investigación, nos muestran propuestas diversas que hemos agrupado como: demandas sociales referidas a la infraestructura y al medio ambiente que rodea las escuelas; proyectos sobre aspectos pedagógicos-institucionales con relación al ámbito escolar y proyectos que llamamos político-ideológicos por que no están referidos a ninguna necesidad o demanda material.

Entre los primeros proyectos la demanda o crítica que encierran apelan por ejemplo a la construcción de salas de biblioteca o gimnasios, la gratuidad del boleto estudiantil o la necesidad de contar con bolsas de trabajo para los egresados de la escuela secundaria y a la erradicación del polo petroquímico que contamina los barrios al sur del centro de la ciudad; la adecuación del transporte público para discapacitados; la creación de centros asistenciales y recreativos para barrios alejados; entre otros. Entre los segundos podemos destacar proyectos vinculados directamente a lo pedagógico, tales como la necesidad de contar con gabinetes multidisciplinarios en las escuelas; la inclusión de materias de informática; la enseñanza de primeros auxilios y de educación sexual. Finalmente, entre los proyectos de carácter simbólico o ideológico por ejemplo el cambio de nombre de calles y establecimientos escolares que recuerdan a figuras de la historia cuestionadas por la nombres de personajes respetados; la necesidad de recordar la memoria del genocidio de la última dictadura preservando lugares o transformando los espacios de la ciudad y la modificación de la bandera actual de la ciudad que simboliza la corona española en su águila negra, por otra que incluya al cóndor como emblema de la libertad americana.

Contradiciendo la mirada evolucionista que presupone intereses particulares progresivamente complejos según las edades; los proyectos que presentan tanto los niños de la escuela primaria como los jóvenes

10 Un proyecto de ley es toda moción destinada a crear, modificar, sustituir o suspender una ley, institución o norma de carácter general. Los proyectos de resolución engloban aquellas decisiones del cuerpo legislativo sobre temas de su incumbencia (responder solicitudes de particulares, otorgar acuerdos, decidir la composición u organización del cuerpo, entre otras). Los proyectos de declaración, por último, contienen proposiciones que reafirman las atribuciones de la legislatura, expresan la opinión del cuerpo sobre cualquier hecho de carácter público o privado, o bien encomiendan al Poder Ejecutivo la realización de un acto en un tiempo determinado. 
adolescentes trascienden las demandas específicas externamente adjudicadas por el mundo adulto. Por el contrario mayoritariamente, los proyectos expresan medidas prácticas que materializan los principios de la modernidad, es decir que incluyen el horizonte de la justicia, la igualdad y la solidaridad en una sociedad que se percibe fragmentada.

La apropiación de las ideas rectoras de la ideología de la modernidad, en el contexto de la construcción histórica del papel estatal en una sociedad segmentada a la que hiciéramos referencia, produce una intensa polémica acerca de lo que corresponde que sea concebido como bien común y, por ende, valioso. Ella se plasma especialmente en el debate al interior del recinto parlamentario. En éste, los jóvenes deben sopesar y discutir argumentadamente las iniciativas propias y ajenas, poniendo en juego capacidades retóricas y argumentativas a fin de sostener y convencer a los otros estudiantes-legisladores.

Es precisamente la concentración de iniciativas en los temas vinculados a la reparación de las condiciones materiales de vida, visualizadas como impedimento al ejercicio pleno de los derechos, la que señala cuán imbricados resultan los proyectos de niños y jóvenes en la historicidad de la construcción de la intervención pública. El interés general o bien común, refiere por tanto, no solamente a los aspectos regulativos que le corresponde aplicar al Estado sobre el cuerpo social (típicos de la concepción liberal), sino igualmente a las medidas de justicia distributiva que permiten la participación ciudadana a través de la provisión de bienes materiales y simbólicos.

El carácter abierto y polémico de cada sesión señala un derrotero que no puede ser ensayado ni previsto con anterioridad. En cada secuencia de debate resultan implicados los criterios de pertinencia (¿qué nos corresponde hacer?) y de jerarquía ó prioridad de las iniciativas (¿qué debemos o podemos hacer?), señalando el viraje del legislador desde aquel rol de vocero y redactor de intereses y demandas, a éste de co-responsable de la actividad estatal. ${ }^{11}$ En esta instancia el registro etnográfico los muestra compenetrados con la tarea de evaluar los motivos de cada decisión en el marco de la totalidad de proposiciones. Bajo el sustrato de una jerarquía implícita de prioridades, en la que se reactualiza la acepción del bien público como reparación por parte del Estado, los proyectos relativos a temáticas pedagógicas, o los

11 Es importante destacar que ése es el cometido de lo que aparece como un entrenamiento cuyo objetivo se expresa en la consigna «legisladores por un día», con el que se promociona el programa en las escuelas. 
que de modo genérico hemos denominado político-ideológicos, resultan poco atractivos para el grueso de los alumnos-parlamentarios.

Tal es el caso de una de las sesiones donde una escuela presenta un proyecto (entre otros siete,) que pide la incorporación de la materia informática en la currícula de nivel secundario. Los argumentos que lo sostienen aluden al derecho a una educación de calidad e igual para todos. Sosteniendo que la actualización en este sentido está en «la base de una nueva ciudadanía». No obstante la implicancia pedagógica de la iniciativa, obtiene el voto negativo de los presentes. Los oradores que deniegan su aprobación, siguen la línea de razonamiento según la cual la alimentación y la seguridad son anteriores a solicitar recursos para la computación, alegando que si «no hay presupuesto para docentes, incorporar una materia como ésta aumentaría aún más el gasto». Consecuentes con el juicio, aprueban con un debate expedito la moción que tiene por objeto la implementación de comedores escolares obligatorios en barrios carenciados de la ciudad, aún cuando esta propuesta también comprometería el presupuesto estatal. Esta preocupación, se impone por la abrumadora evidencia del deterioro socio-económico de la población, y permite interpretar que la noción de bien público opera en un doble registro simbólico. Por una parte, expresa la solidaridad y responsabilidad que las nuevas generaciones manifiestan hacia quienes están excluidos del modelo vigente. Por otra, resta importancia (o considera ajeno) a las propuestas que algunos jóvenes impulsan sobre problemáticas y soluciones referidas al contexto pedagógico escolar, al concebirlas como acotadas y específicas.

Efectivamente, al calor de estos debates podemos volver a la pregunta que interroga acerca de la particularidad de lo que es el bien común para niños y jóvenes y el por qué de la no consideración de la vida escolar como una responsabilidad propia al momento de decidir por todos y para todos.

\section{EL DEBATE SOBRE LA ACCIÓN POLÍTICA DE LOS JÓVENES: TEMAS CONVOCANTES Y REPRESENTATIVIDAD}

\section{a) Los temas y el campo de acción}

En el espacio escolar, el protagonismo político de los jóvenesadolescentes encuentra su lugar «natural» en los centros de estudiantes. Si bien estos no son entidades homogéneas (dada su diversidad relativa a las tradiciones que los configuran), las discusiones y pre- 
ocupaciones que se dan dentro de éstos suponen el derecho a la organización autónoma (o relativamente autónoma) del estudiantado. ${ }^{12}$

Como organizaciones institucionalizadas, los centros han tenido una lenta recuperación luego de la restitución de la democracia en la Argentina, aunque nuestra investigación documenta la revitalización y el incremento de la movilización estudiantil en los últimos años, luego de los sucesos del 2005 anteriormente mencionados. El popularmente llamado «efecto Cromagnon» constituye un parteaguas en la visibilidad social del sector estudiantil. Este hecho implicó una grieta en el orden institucional en el que se desarrollaba la educación secundaria, manifestándose en la fugaz suspensión de las jerarquías, la apropiación del espacio por parte de los estudiantes, la subversión del tiempo dedicado a la enseñanza curricular y particularmente al protagonismo que adquirieron los jóvenes al demandar de modo directo por sus derechos. Si bien las peticiones giraron en torno a la seguridad y el mantenimiento de los edificios escolares, ello no agotó la movilización que trascendió esta circunstancia, exigiéndose al Estado el compromiso con la educación pública. Las formas de protesta franquearon los métodos pacíficos habituales y exhibieron medidas más acentuadas como cortes de calles, la toma de edificios escolares, abrazos a las escuelas, entre otras formas de lucha. ${ }^{13}$

Estos sucesos activaron el desarrollo cotidiano de las organizaciones estudiantiles, tiñendo conflictivamente las interpretaciones de jóvenes y adultos tanto en relación con el papel de la dirección de los

12 En la Argentina, los centros de estudiantes como forma de organización de segundo grado de los estudiantes secundarios, son tributarios de una tradición asociativa protagonizada por estudiantes universitarios desde mediados del siglo XIX. En los comienzos del siglo pasado, los alumnos asistentes a colegios nacionales fueron los primeros en darse este modo de organización, experiencia que se multiplicaría en otras modalidades del nivel medio público a partir de la reforma universitaria de 1918. Su continuidad estuvo sujeta a los avatares políticos del país, siendo prohibidos por distintos gobiernos militares y civiles.

13 La reconstrucción a través de medios gráficos nos permite precisar que el conflicto se desató antes de iniciarse el ciclo lectivo (febrero de 2005) y alcanzó su máxima expresión a finales del mes de mayo del año 2005 con una marcha hacia Plaza de Mayo en la que confluyeron docentes y estudiantes. Si bien los sucesos se desarrollaron principalmente en la Ciudad de Buenos Aires, su posición estratégica de «doble jurisdicción» - Capital de la Nación y Ciudad Autónoma - implica una mayor visibilidad de sus asuntos en el ámbito nacional. 
colegios, como al mismo movimiento estudiantil. Al interior de éste, las posiciones se dividieron entre los grupos «combativos» y aquellos que juzgaban excesivo el tono de la protesta y el contenido de las propuestas. Puede decirse sin temor a dudas que durante ese período los jóvenes fueron protagonistas de la defensa de lo político, ya que su movilización y demandas desbordaron las reivindicaciones contingentes para orientarse hacia la defensa del bien público.

Recobrada la dinámica normal de las instituciones y centros, el registro etnográfico recupera los obstáculos y limitaciones que los estudiantes atribuyen a sus organizaciones para convertirse efectivamente en un sector representativo del estudiantado y genuinamente reconocido por los adultos como parte de «la comunidad escolar». Como adelantamos, estas dificultades se encuentran en sintonía con el descrédito de la actividad política general instalada en el sentido común ciudadano, exigiendo a sus dirigentes y militantes la búsqueda permanente de respuestas para enfrentar el menoscabo de la actividad. En el caso de los jóvenes, esta conflictiva construcción discurre a través de la insatisfacción que en muchos de ellos provocan las formas de la participación y los mecanismos de representatividad.

A fin de precisar el análisis, es posible señalar un arco de posiciones diversas respecto a la actividad, los contenidos y la orientación que corresponde dar a los centros de estudiantes, los que encuentran su particularidad más notoria en el legado de tradiciones u orientaciones político-pedagógicas que se han desarrollado en este campo y con las cuales los estudiantes se identifican. La presencia de tales tradiciones en el accionar estudiantil resultan también variables según el grado en que son reconocidas e incorporadas a la historia institucional, de la cual devienen distinciones y marcas a través de las cuales se identifican. Siguiendo las categorías locales, es posible trazar ciertos derroteros en el accionar político de los centros, según pertenezcan a la órbita de las universidades nacionales («somos del Pellegrini»); a escuelas públicas que congregan los tres niveles de enseñanza («los del normal») —instituciones ambas reconocidas por su prestigio y por las prácticas políticas de sus estudiantes - o, bien, a establecimientos comunes en los que se disuelve la historicidad del movimiento estudiantil y de la institución, y en los cuales los proyectos políticogremiales resultan sujetos a los vaivenes de la orientación que le imprimen las autoridades escolares en la escala local.

En la vida interna de los centros de estudiantes, la investigación registra en la actualidad la preocupación compartida entre dirigentes, mili- 
tantes y simpatizantes, acerca de las formas más adecuadas — genuinaspara sostener y reavivar la acción política manteniendo el protagonismo del sector. En este punto, las controversias acerca de los intereses que los centros deben encauzar, se organizan según una construcción simbólica que delimita el «adentro» y el «afuera» del ámbito escolar, configurando en su oscilación la legitimidad y la politicidad que puede atribuirse a tales preocupaciones. Aunque esta controversia puede marcar una tensión entre diferentes posiciones, el trasfondo compartido de las discusiones se apoya en la idea de preservar y profundizar la democracia en términos generales.

En un foro virtual gestado entre estudiantes de una escuela dependiente de la Universidad de Buenos Aires, argumentos ríspidos entre participantes polemizan acerca de la jerarquía de las acciones a encauzar, comprometiendo en tales razonamientos el alcance de lo político que los jóvenes pueden legítimamente adjudicarse. Una secuencia del debate incluye las siguientes participaciones.

Estudiante 1 (dirigente estudiantil):

No, primero democratizamos adentro, y después vemos qué hacemos afuera, primero los baños, y después vemos si nos cogen con el presupuesto, primero un bar más limpio, y después vemos si hay desaparecidos en democracia.

Estudiante 3(dirigente estudiantil):

La diferenciación entre el adentro y el afuera es ridícula, y [pienso] que no se pueden aislar las esferas. Aunque no lo creas, para tener un buen bar también hace falta ir a una marcha por otras cosas. [Estoy] contra esa distinción absurda del adentro y el afuera, contra esa boludez de privilegiar el adentro, y contra eso de separar «lo político» de lo «no político», cuando no ir a una marcha es tan político como ir.

Entre los dirigentes estudiantiles que privilegian las temáticas relacionadas con «el adentro», el centro debería orientarse hacia las actividades deportivas, artísticas y lúdicas (recreativas) o bien, hacia iniciativas comprometidas con la preservación e higiene del edificio y la ampliación de servicios sin fines de lucro, tales como jornadas culturales, biblioteca, fotocopiadora y bar. Estas acciones buscan afirmar los lazos de sociabilidad entre los jóvenes a partir del compromiso entre pares, rechazando el calificativo de políticas en sentido amplio, por la asociación que perciben entre éste término y la militancia partidaria. 
Quienes postulan una posición antagónica, visualizan la perspectiva recreativa como la concepción de «un club» con la consecuente postergación de lo político. En su razonamiento, el centro de estudiantes debe ser un espacio "combativo», delimitado por categorías tales como «lucha», "poner el cuerpo», «objetivos» (en tanto plataformas o programas), y abocado a formas de acción centradas en las «tomas», las «marchas» y los «cortes de calle». Las principales demandas que enarbolan se refieren a la política educativa que afirma garantizar la igualdad de oportunidades, reclamando un incremento significativo del presupuesto, que es correlativo con el derecho de «hacer valer los derechos». ${ }^{14}$

La demanda de una educación que encarne los valores de la ley 1420, es decir «laica, gratuita y al servicio del pueblo», muestra a los estudiantes «combativos» abrevando en el mito fundador del sistema educativo argentino. En esta misma línea, reclaman «orientaciones libres e irrestrictas» para la escuela secundaria acorde a una concepción universal de la escuela pública, y elaboran razonamientos antagónicos a la reforma del sistema educativo nacional, tanto sea la sancionada en 1992 como la recientemente aprobada en 2006. Ambas leyes son concebidas por este sector como "privatistas», es decir, orientadas a promover las relaciones de mercantilización en detrimento de la protección estatal de la «igualdad de oportunidades», ${ }^{15}$ motivo por el cual es legítimo asimismo confrontar con las empresas educativas y la iglesia católica como actor principal del sector de la educación privada en la Argentina. Por el contrario, las demandas de los docentes, a quienes visualizan como «trabajadores de la educación», ameritan trascender la frontera sectorial de las peticiones estudiantiles, para invocar la «defensa [común] de la educación pública» en tanto derecho ciudadano.

Para este grupo, el tema de la «memoria» surge como un interés recurrente que enmarca la defensa de la democracia, la que exige nuevamente avanzar más allá de la propuesta estatal vigente - a la que acusan de despolitizar los derechos humanos circunscribiéndolos al

14 En el tópico incluyen inversión en infraestructura escolar; ampliación de los programas de becas y viandas; mayor cobertura para los estudiantes respecto al transporte público; oposición frente a la disminución de números de cursos, entre otros.

15 Se trata de la Ley Federal de Educación, sancionada durante el gobierno del Presidente Menem y de la Ley Nacional de Educación, aprobada a fines de 2006 como contrarreforma de la primera. 
derecho a la vida - ligando las reivindicaciones actuales con el proyecto sociopolítico sostenido treinta años atrás por un sector de la juventud. $^{16}$

Particularmente en establecimientos con tradición de compromiso social, las propuestas del centro avanzan en la dirección de profundizar la autonomía de la organización reclamando a los directivos el «control» en el reparto de las viandas y las becas que reciben los estudiantes, y la suspensión de la «seguridad privada en las escuelas», personal que es acusado de obstaculizar las acciones colectivas propositivas de los jóvenes.

En una posición intermedia del espectro antes esbozado, los simpatizantes de centros de estudiantes de escuelas públicas, embarcados en la confrontación recurrente con directivos para garantizar la existencia de la entidad gremial y la orientación que corresponde darle, proponen un «equilibrio entre el adentro y el afuera». La preocupación por los «asuntos estudiantiles» resulta válida tanto como la de los «asuntos externos», siempre y cuando la balanza no se incline en detrimento de uno de los extremos. Garantizar una adecuación a lo específicamente escolar resulta crucial en aquella confrontación, motivo por el cual la frustración de tales expectativas - fundamentalmente de aquellas acciones que involucran el «adentro» escolar- es origen de duras críticas hacia el centro de estudiantes, como puede leerse en el siguiente comentario extraído de una entrevista con una joven, ex militante del centro.

Desde principio de año están diciendo que van a hacer una jornada de limpieza, nunca vi ni un cartel que diga nada sobre la jornada de limpieza. Entonces son cosas que vos decís no funcionan... Para que un CE de estudiantes funcione equilibradamente tiene que haber tanto de lo interno como de lo externo para equilibrar las dos cosas... porque nosotros en definitiva somos el Liceo [número de la escuela] y tenemos que sustentar lo que tenemos, cuidar lo que tenemos y hacer que los chicos que capaz no tienen idea de lo que pasa en el mundo se enteren y ese estilo de cosas, que este año la verdad no están haciendo nada».

Esta perspectiva es coherente con la lógica de sentido común que define lo que es pertinente según las edades de la vida, resultando desfa-

16 Esta preocupación es subsidiaria de la historia política de nuestro país y su idea de justicia remite a una experiencia inédita en la Argentina como fue el juicio a la junta militar. 
sado para la etapa adolescente que se transita demostrar desmedido interés por asuntos extraños a la experiencia vital. Así, si bien las cuestiones del «afuera» deber ser conocidas y tenidas en cuenta, el ámbito de competencia de los jóvenes es circunscrito por un «adentro» específicamente escolar. ${ }^{17}$ En ausencia de prácticas estudiantiles arraigadas en la institución, y obligados a legitimar las acciones frente a una autoridad reacia a otorgar credibilidad, quienes aspiran a dirigir estos centros se ven compelidos a recuperar y recrear una - también esquiva - identificación con los intereses genéricos del «estudiantado», procurando eliminar toda referencia partidaria en la política.

Es precisamente esta evitación, la que conduce a un sector del estudiantado a considerar «sospechosa» cualquier petición o confrontación con el Estado, pues ésta sería una actividad de los partidos políticos. Así, mientras sus compañeros militantes sostienen la necesidad de efectuar reclamos por las condiciones edilicias y la provisión de recursos, éstos proponen como medida práctica autogestionar los fondos en colaboración con las autoridades y organizar una actividad estudiantil que sustituya la indiferencia gubernamental.

De un modo análogo, no resultan homogéneos los lazos que unen a los estudiantes con sus pares comprometidos de los años 70. En tanto para los que se autocalifican de «militantes», el término mismo de «estudiante» traza una continuidad generacional con aquéllos; para otros, resulta prioritario reconocer formas alternativas e igualmente válidas de serlo.

La reconstrucción de esta línea de pensamiento al interior de los centros de estudiantes en proceso de formación, impide hacer un juicio homogeneizante respecto a la posición que las jóvenes generaciones tendrían en torno a la tensión de lo político/la política. En el caso en que estamos analizando, la legitimidad del accionar estudiantil depende precisamente de su capacidad para neutralizar y rechazar la política entendida como la organización institucionalmente prevista de los intereses antagónicos en la sociedad, en pos de fundamentarse en un genéri-

17 Algunos de los dirigentes reconocen que planteos como «fuera yankis de Irak» no tienen nada que ver con ellos y que la gran mayoría «no los entiende» por ello propone retomar las demandas de los «alumnos» para contar con su apoyo, refiriéndose a un centro que brinde opciones recreativas y además se ocupe de que el colegio esté en condiciones materiales adecuadas para llevar adelante los procesos de enseñanzaaprendizaje (función que otrora correspondía exclusivamente a la cooperadora). 
co interés estudiantil orientado hacia la intimidad —recreativa o administrativa- de la institución escolar.

\section{b) Las formas de organización y su legitimidad}

Los centros de estudiantes se organizan a través de estatutos que siguen las disposiciones legales vigentes en las jurisdicciones. Si bien son redactados por los estudiantes, que cuentan para ello con cierto margen en la definición de la organización deseable, generalmente adoptan la forma de la democracia representativa sugerida por la normativa, en analogía a las instituciones del Estado. ${ }^{18}$ Aunque existen variaciones estatutarias, en líneas generales el reglamento dispone que todos los estudiantes regulares, a modo de pueblo soberano, confían el poder de decisión sobre los asuntos comunes a otros estudiantes designados a través del voto anual. Los candidatos deben conformar o participar de agrupaciones estudiantiles y presentar programas, tal como en las campañas políticas. Al mismo tiempo prevé dos categorías de representantes con voz y voto: los integrantes del comité organizador y los delegados por curso, quienes asumen el compromiso de reunirse semanalmente en asambleas ordinarias con el objetivo de deliberar acerca de las inquietudes y necesidades de los estudiantes.

A pesar de contar con este respaldo normativo, fruto del esfuerzo post dictatorial por ampliar los márgenes de participación democráti-

18 En el caso de la Provincia de Buenos Aires (res. 4900/05), el modelo de estatuto establece la Asamblea de Representantes (compuesta por los delegados de cada curso) como órgano deliberativo y la Comisión Directiva (presidente, vicepresidente, secretario, tesorero y vocales), la que debe ser propuesta en listas y acreditada mediante elecciones por voto secreto no obligatorio. Asimismo, incluye el cargo de «Consejero Docente» con fines consultivos respecto a la normativa vigente y al quehacer institucional, cuando le es solicitado por la Asamblea. En la Ciudad de Buenos Aires, la regulación de los centros de estudiantes secundarios busca garantizar el derecho de asociación civil avalado por la Constitución Nacional de 1994. Su propósito principal gira en torno a normalizar el modo de organización de los jóvenes escolarizados en el nivel medio, para impedir la actuación de resabios autoritarios que obturen su participación. Así, el centro es reconocido jurídicamente como un espacio escolar cuyo fundamento es promover valores democráticos entre alumnos secundarios y establecer un puente entre la escuela y la sociedad mayor. 
ca, nuestra investigación documenta la existencia de una frustración reiterada a la hora de garantizar los cargos electivos, principalmente en relación con la convocatoria y la permanencia de los estudiantes. Tratar de comprender la problemática implicada tras opiniones según las cuales «el estatuto no alcanza» para legitimar las acciones colectivas de los estudiantes, esgrimida por muchos jóvenes, conduce a nuestra investigación a interrogantes que enlazan la especificidad de la problemática del protagonismo juvenil con el debate social más amplio acerca de la capacidad de las formas políticas para encauzar la voluntad general. Se trata, en síntesis, de los esfuerzos — en sí mismos, imposibles - de superar el efecto de distancia, de diferenciación y de opacidad entre representante y representado, que subyacen a la teoría y la práctica liberal del voto y la representación. Souza Santos destaca el carácter paradójico de esta pretensión, recuperando la afirmación de Kant, «la representatividad de los representantes es tanto mayor cuanto menor sea su número y cuanto mayor sea el número de los representantes... Por la propia naturaleza de esta teoría... el interés general no puede coincidir, casi por definición, con el interés de todos». ${ }^{19}$

La preocupación por la forma que debe asumir el protagonismo estudiantil y, concomitantemente, por la legitimidad de las decisiones que se adoptan a título del grupo, es motivo de recurrente discusión, dando lugar a posiciones heterogéneas que discrepan polarizadamente. Mientras para algunos la democracia representativa implica la concentración de poder en manos de uno pocos, la democracia directa favorece el incremento de la participación. En esta perspectiva, la horizontalidad de las relaciones significa un avance de la igualdad e inclusión, expresada en el derecho a la palabra («todos podemos hablar»). Para otros, por el contrario, el ejercicio de la democracia directa es entendido como una carencia de organización («partimos de la nada») que oculta bajo su amplitud, la voluntad de aquellos estudiantes que tienen capacidad de protagonismo sobre el trasfondo de una escasa intervención del colectivo estudiantil. Desde esta posición, la creación de mecanismos representativos ofrece un momento de decisión a aquellos que permanecen en silencio, cuanto menos en la instancia de elegir sus delegados y representantes gremiales.

Las situaciones en que las autoridades escolares obstaculizan la conformación de los centros o las acciones programadas por éstos,

19 Souza Santos recupera aquí el artículo $1^{\circ}$ del Proyecto de Paz Perpetua de 1795, de Kant (Sousa Santos, 1985). 
ofrecen una instancia privilegiada para analizar el atolladero en que se encuentran las propuestas por conformar mecanismos de participación amplios y consensuados. En ellas, los dirigentes electos son recurrentemente acusados de «no hacer nada», produciéndose una permanente deserción de dirigentes y delegados. Quienes permanecen como grupo activo con el propósito de impulsar el centro, se ven compelidos a prescindir de los mecanismos formales de organización (de hacerlo, deberían convocar a elecciones); es decir, se imponen formas de «participación directa» igualmente carentes de legitimidad, desde la perspectiva del estudiantado restante. Si las formas de democracia directa se basan en la ilusión de la total participación del conjunto de los estudiantes (un estudiante=un voto), el esfuerzo de los comprometidos no tiene destino. En un círculo vicioso, se ven conducidos a la búsqueda de mecanismos que efectivicen la plena «transparencia» (difundir actividades, recolectar firmas que apoyen las decisiones, realizar asambleas extraordinarias, establecer modalidades de consulta, etc.) entre los intereses de los militantes y quienes no los son y a enfrentar nuevas discusiones sobre posibles estrategias.

A su vez, la ausencia de agrupaciones que se postulen para las elecciones, puede dar motivo a la disolución de la organización estudiantil o ser objeto de intervención de las autoridades, quienes desde sus espacios, motorizarán la formación de agrupaciones orgánicas afines a sus intereses.

En sus formas de expresión cotidiana, el dilema se vuelve irresoluble. Como señalara Souza Santos (1985) para la problemática política contemporánea, el alter ego del espontaneísmo y la autenticidad con la que se percibe los intereses particulares es la apatía y la desmovilización política. Lo que se sustrae en la polémica es precisamente el carácter construido - no transparente-, a través del disenso, de la voluntad general.

\section{c) El debate interno sobre criterios de participación: las edades, la retórica, los liderazgos}

En el espacio escolar, la utilización de las categorías genéricas «estudiantes» y «compañeros» resulta recurrente, sea como parte de las exhortaciones que se dirigen entre sí los estudiantes, apelando a la construcción de una homogeneidad de intereses y preocupaciones que borra las diferencias etáreas e ideológicas, sea para diferenciarse de quienes ubican como «adultos» y «autoridades». La dinámica política 
estudiantil no es, sin embargo, monocroma, aunque la preocupación por desdibujar o rechazar, según el caso, las afinidades partidarias y el desempeño protagónico que muchos estudiantes ostentan por experiencias políticas iniciales en tales ámbitos, ejerce un efecto de censura orientado a rescatar —idealizadamente - una voz y un interés auténticos, por no contaminados, del grupo de pertenencia. Soterrados bajo estas preocupaciones explícitas, es posible rastrear otros criterios internos que orientan la participación, los que establecen una distancia entre el «recién llegado» y aquel que lleva un periodo más prolongado en el centro («vos porque venís hace unos meses, pero yo que vengo desde el año pasado»), frente a la cual se dirime la credibilidad y la eficacia de lo dicho.

Si bien los estudiantes más jóvenes, los «novatos», constituyen una masa crítica a la cual convocar y movilizar en los períodos de intensa actividad política —convocatorias, campañas electorales, marchas y movilizaciones - cuyas afinidades disputarán los «dirigentes-militantes», el destino predominante de su participación en las actividades de índole política es mantenerse (o ser mantenidos) en el silencio.

El derecho a la palabra y su eficacia simbólica, como elementos constitutivos de la acción política, son valorados y recreados en los términos de la problemática estudiantil, y sobre su consideración los estudiantes se autorizan o inhiben la expresión de opiniones. El registro etnográfico reconstruye a los jóvenes de los primeros años intentando infructuosamente ser escuchados en una reunión («sería bueno que todos pudiéramos hablar»), o ser objeto de desestimación mediante miradas, muecas y gestos cómplices, situación que termina por inhibirlos («iviste la boludez que dijo?»). El temor que les infunde «quedar mal» ante la mirada de quienes conocen mejor las reglas del juego, correlativo a los intentos de jerarquizar la participación, pueden no obstante ser puestos en cuestión por los «recién llegados», quienes retoman la categoría «compañeros» para reivindicar su condición de par y copartícipes de la construcción de un espacio común.

En el otro extremo de las competencias discursivas, la imposición a través del tono de voz y la elocuencia oratoria, propios de los más grandes, garantizan un turno en el debate y la posibilidad de ser escuchado, siempre que se evite el riesgo de emular la seducción del discurso político. De allí que, aunque paradójico, un desempeño exitoso del protagonismo estudiantil puede ser objeto de crítica, al desequilibrar lo que se consideran los rendimientos discursivos normales entre los estudiantes. Recuperando nuevamente en este campo la paradoja 
que hemos expuesto en los acápites anteriores, la eficacia de la palabra como constructora del sentido del mundo puede acabar destruyendo la buscada «autenticidad» del mundo estudiantil.

\section{CONCLUSIÓN: EL SENTIDO DE LA POLÍTICA PARA LAS NUEVAS GENERACIONES Y EL MUNDO ESCOLAR COMO ÁMBITO DE DISCUSIÓN}

Señalamos, en la introducción, que nuestro interés por documentar el protagonismo político de las nuevas generaciones reconoce una preocupación de más amplio espectro relativa a la eventual democratización de la escuela, como la comunidad genuina de pertenencia de los estudiantes. Fundamentándose en la reflexión académica contemporánea acerca de lo político —entendida como el campo de construcción de la vida en común (la comunidad y su regulación)—, es posible interrogarse por qué la escuela como «ámbito de la vida en común» de estos sujetos, no puede ser pensada en su construcción y regulación con la participación progresiva de éstos últimos. Debemos recalcar que ensayar el horizonte teórico que abren estas preguntas no implica en ningún sentido negar la necesidad de la protección adulta responsable que tienen las nuevas generaciones; ni en modo alguno proponer la autonomía política de este sujeto. Se trata de deconstruir una franja de indeterminada dependencia, sustituyéndola por una —-también por el momento teórica - transicionalidad, capaz de distinguir los niveles crecientes de agencia que van alcanzando en sus apropiaciones del mundo social.

En tal sentido, la profundización del registro etnográfico en lo que refiere a las capacidades propositivas de los jóvenes y a los debates complejos que esgrimen en relación al bien público y la legitimidad de las formas políticas para canalizar su realización, no hizo sino ampliar especularmente el interrogante acerca de los motivos por los cuales aquéllas energías no encuentran en la institución escolar su continente propicio. De modo complementario, en qué medida las prácticas institucionalizadas para la expresión de los intereses políticos de los jóvenes que hemos documentado, resultan orientadas en dirección a aquélla posibilidad.

En sus versiones más progresistas, las disposiciones acerca del gobierno escolar reservan éste a la comunidad de directivos, docentes y padres o apoderados, excluyendo a los alumnos en función de su minoridad, según el razonamiento jurídico al que hemos hecho referencia. La 
participación prevista para éstos últimos en el ámbito escolar se canaliza a través de los centros de estudiantes y en los consejos de convivencia. Como documentamos en el punto anterior, los centros resultan compelidos a fundamentarse ya sea en los intereses genéricos y, por tanto, sectoriales, de los «estudiantes» —esto es, a devenir propiamente una agrupación gremial-, ya sea a proyectarse en un -igualmente genérico- afuera, confluyendo con la demanda social y política mayor. En la perspectiva que pretende encauzar las acciones hacia el adentro de la vida escolar, las posiciones gremialistas descalificadas por los más politizados como de entretenimientos o de actividades culturales, consiguen plasmarse con dificultad, del mismo modo que tampoco es masivo la aceptación del discurso político que expresan las corrientes que dirigen los centros. A lo largo de esta oscilación, las tensiones entre lo político estudiantil y la política estudiantil (asociada a los partidos y las tradiciones combativas) pueden leerse entonces como expresiones de la imposibilidad de encontrar destino en la institución escolar, entendida como una comunidad heterogénea y plural, frente a la cual asumir responsabilidades progresivas en su construcción. Esta deviene, o bien el lugar del antagonismo o alianza entre "posiciones» (directivos, padres, estudiantes), o bien un espacio indiferenciado de la totalidad social, sin especificidad alguna para reclamar para sí y para sus sujetos constituyentes.

Resituar lo que es propio de esta comunidad resulta un eslabón imprescindible para encontrar soluciones transitorias a la paradoja del protagonismo estudiantil que enlaza la representación, la decisión y la autenticidad, siempre al riesgo de fundirse en la apatía política mayor, de la cual las nuevas generaciones no son responsables.

Por otra parte, la riqueza de los temas y debates que los estudiantes se permiten desarrollar en la legislatura, correlativa a los múltiples ámbitos en los que la sociedad contemporánea involucra la construcción del bien común, contrasta con aquellos que son permitidos o formulados como objeto de debate en los centros escolares y los consejos de convivencia. ${ }^{20}$

Sin embargo, señalamos que dinámica del debate parlamentario produce un efecto paradójico en lo que refiere a nuestra interrogante.

20 Los alumnos no encuentran en los consejos de convivencia un espacio para canalizar sus propuestas, ya que, en sus términos, se pasan todo el año discutiendo los problemas de sanciones disciplinarias puntuales y de vestimenta de los alumnos. 
Al ubicarlos, siquiera como simulacro, en la responsabilidad de decidir y legislar para todos y por todos, tiende a difuminar los intereses relativos al ámbito escolar por considerarlos demasiado puntuales o específicos, frente a las concepciones dominantes del bien común como reparación de daños o inequidades sociales. Más aún, si bien la legislatura es escenario del potencial de este sujeto para preocuparse por el espacio público, la autoría de los proyectos que resultan de interés para los legisladores será omitida, bajo el supuesto de que éstos constituyen «ensayos para la civilidad futura», y no expresiones auténticas de participación ciudadana.

Recuperar la concepción de la escuela como espacio público, ${ }^{21}$ supone el doble desafío de conceptualizarla como espacio político, retomando el sentido productivo del poder que fuese eclipsado por la acepción de control y dominación, la que a su vez ameritaba la protección de la infancia hasta su «mayoría de edad». Si aquél sentido remite a la capacidad de lo político para reformular racionalmente las condiciones de la convivencia, hemos documentado las posibilidades e intereses progresivos que las nuevas generaciones expresan en torno a su construcción.

BuENos Aires (ARgENTINA), MARZO 2009

RECIBIDO: MARZO 2009

ACEPTADO: ABRIL 2009

\section{REFERENCIAS BIBLIOGRÁFICAS}

AdORNO, TEODOR (1973): Tabúes relativos a la profesión de enseñar. En: Consignas. Buenos Aires: Amorrortu.

Batallán, Graciela (2007): Docentes de infancia. Antropología del trabajo en la escuela primaria. Buenos Aires: Paidós.

21 En otro trabajo hemos argumentado esta posibilidad es función de la triple connotación que contiene la escuela en tanto comporta: a) la obligatoridedad del Estado en la distribución igualitaria de la educación como un bien social, b) la constitución de un ámbito no doméstico para el desarrollo progresivo de los vínculos sociales entre adultos y jóvenes (conformándolos en un semi público) y; concatenado a lo anterior, c) el reconocimiento de la particularidad de la institución educacional, como co-participada entre madres/padres/tutores (en tanto usuarios indirectos) y el Estado (Batallán y Campanini, 2005). 
BATALLÁN, GRACIELA et al. (2005): «Estudiantes, legisladores, piqueteros y chicos del pueblo: discusiones sobre la infancia y la juventud en prácticas recientes de democracia directa y representativa». I Congreso Latinoamericano de Antropología, Asociación Latinoamericana de Antropología (ALA). Rosario, 11 al 16 de julio 2005.

— y Silvana CAmpanini (2005): «Infancia, juventud y política. Aproximación conceptual en el marco de la democracia participativa». I Congreso Latinoamericano de Antropología, Asociación Latinoamericana de Antropología (ALA). Rosario, 11 al 16 de julio 2005.

(directora) (2004): «Proyecto F134: infancia, juventud y política. La participación de un 'no ciudadano' en el espacio público». Secretaría de Ciencia y Técnica de la Universidad de Buenos Aires, 2004-2007.

- - RENÉ VARAS (2002): Regalones, maldadosos e hiperkinéticos. Categorías sociales en busca de sentido. La educación de los niños de cuatro años que viven en la pobreza urbana. Santiago: Mineduc, PIIE y LOM.

Bourdieu, Pierre (2000): «La 'juventud' es sólo una palabra» En: Cuestiones de sociología. Madrid: Istmo.

De Souza SANTOS, BoAventuRA (1998): De la mano de Alicia. Lo social y lo político en la posmodernidad. Bogotá: Siglo del Hombre Editores y Universidad de los Andes.

FeIXA, CARLes (1998): De jóvenes, bandas y tribus. Antropología de la juventud. Barcelona: Ariel.

Fraser, NANCY (1992): «Rethinking the Public Sphere: A contribution to the Critique of Actually Existing Democracy». En: Habermas and the Public Sphere. Cambridge: MIT Press.

HABERMAS, JÜRGEN (1986): Historia y crítica de la opinión pública. México: Gilli.

Laclau, ERnesto y Chantal Mouffe (1985): Hegemony and Socialist Strategy: towards a radical democratic politics. Londres: Verso.

LESKO, NANCY (1992): «Sujetos de la ciencia: el concepto de los adolescentes como el 'otro' en la investigación etnográfica». En RUEDA y CAMPOS (coordinadores): Investigación etnográfica en educación. México: UNAM.

MARTíN BARBERO, Jesús (1998): «Jóvenes: des-orden cultural y palimpsestos de identidad». En CUBIDES y otros: Viviendo a toda. Jóvenes, territorios culturales y nuevas sensibilidades. Bogotá: Siglo del Hombre Editores y Departamento de Investigaciones Universidad Central.

MoufFe, CHANTAL (1999): El retorno de lo político. Barcelona: Paidós.

PADAWER, ANA (2004): «Nuevos esencialismos para la antropología: las bandas y tribus juveniles, o la vigencia del culturalismo». Ponencia presentada al Simposio: Antropología y Juventud. VI Congreso Argentino Antropología Social. Córdoba.

Reguillo, Rosana (2000): Emergencia de culturas juveniles. Estrategias del desencanto. Buenos Aires: Norma. 
Rosanvallon, Pierre (2003): Por una historia conceptual de lo político. Buenos Aires: FCE.

SOMMERS, MARGARET (1996/97): «¿Qué hay de político o de cultural en la cultura política y en la esfera pública? Hacia una sociología histórica de la formación de conceptos». Revista Zona Abierta N77/78. Madrid: Editorial Pablo Iglesias.

SOUZA SANTOS, BOAVENTURA DE (1998): De la mano de Alicia. Lo social y lo político en la posmodernidad. Bogotá: Siglo del Hombre Editores y Universidad de los Andes.

\section{TEXTOS NORMATIVOS}

Resolución N¹51/98 de la Legislatura del Gobierno de la Ciudad Autónoma de Buenos Aires.

Resolución 4900/05. La Plata, 15 de septiembre de 2005. Anexo: Modelo de Estatuto para Centros de Estudiantes de la Provincia de Buenos Aires. 